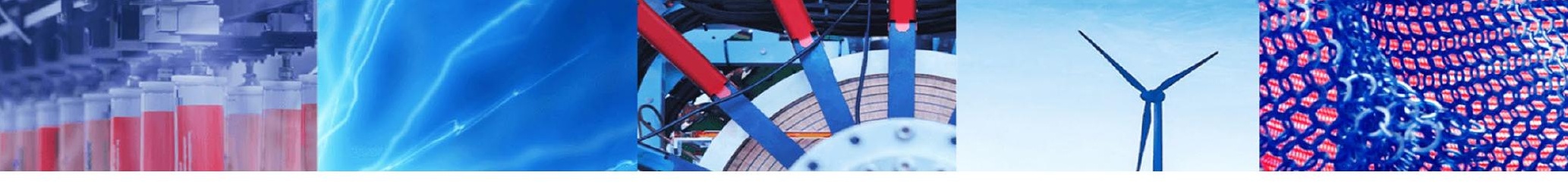

Research Article

\title{
Electrical transport of chalcogenide glassy system: interpretation by Hunt's model and microstructure
}

\author{
Swarupa Ojha ${ }^{1,2} \cdot$ Madhab Roy $^{2} \cdot$ Anil Chamuah $^{3} \cdot$ Koyel Bhattacharya $^{4} \cdot$ Sanjib Bhattacharya $^{3}$
}

Received: 17 December 2019 / Accepted: 13 March 2020 / Published online: 7 April 2020

(c) Springer Nature Switzerland AG 2020

\begin{abstract}
$\mathrm{Ag}_{2} \mathrm{~S}$ doped Sulphur-Tellurium chalcogenide glassy system has been developed and their dielectric properties and electrical conductivity have been studied. Electrical conductivity via hopping of polarons in the present system is found to decrease due to large number of defects. TEM micrographs reveal the formation of $\mathrm{Ag}_{2} \mathrm{~S}_{2} \mathrm{Ag}_{2} \mathrm{Te}$ and $\mathrm{AgTe}_{3}$ nanophases, whose sizes are found to decrease with compositions. Almond-West formalism has been used to analyze the thermally activated nature of conductivity spectra. Hunt's model is used to reveal dielectric relaxation process with composition, which is justified by microstructure, revealed from TEM micrographs. Peak frequency $\left(\omega_{m}\right)$ corresponding to imaginary modulus spectra shows Arrhenius relation. The results may reveal the opening for the development, significance and investigation of electrical and dielectric properties of chalcogenide glassy system.
\end{abstract}

Keywords Chalcogenide glassy system · Electrical transport · Hunt's model · Microstructure

\section{Introduction}

Chalcogenide glassy system is particularly important because of its considerable applications in the field of infrared spectroscopy, lower phonon energy, high value of non-linear refractive indices and excellent glass-forming ability [1-4]. Chalcogenide glassy system exhibits higher electrical conductivity than their oxide counterparts as the high polarizability of sulfur or selenium plays vital role in the conduction process [5-7]. Recent works [7] exhibit that higher electrical conductivity of silver doped glassy systems should be favourable to enhance lifetime of battery material. It is also observed that $\mathrm{Ag}^{+}$doped chalcogenides may improve the ability of development of such glassy system [8]. Chalcogenide glassy system may be the potential candidate for new generation rechargeable batteries as they exhibit higher electrical conductivity at room temperature and wide range of composition flexibility [9, $10]$.

Influence of different impurities in various chalcogenide glassy systems is of great interest of research community [11-15] as it can explore various properties such as switching, memory elements, etc. It is important to note that enhancement of electrical conductivity by hopping of small polarons has been observed as transition metal ions are doped with chalcogenide glassy system [16]. Study of AC conductivity of such glassy system may reveal not only the new horizon of transport phenomenon in localized states in the forbidden gap but also the information about the type of polarization [17-19]. Some works on conductivity spectra and relaxation mechanisms of different chalcogenides have already been reported [17-19]. The vivid description of electrical conduction and dielectric

$\triangle$ Sanjib Bhattacharya, sanjib_ssp@yahoo.co.in | ${ }^{1}$ Department of Electronics and Communication Engineering, OmDayal Group of Institutions, Uluberia Industrial Growth Centre, Howrah, West Bengal 711316, India. ${ }^{2}$ Department of Electrical Engineering, Jadavpur University, Jadavpur, Kolkata 700032, India. ${ }^{3}$ Department of Engineering Sciences and Humanities, Siliguri Institute of Technology, Darjeeeling, West Bengal 734009, India. ${ }^{4}$ Department of Physics, Kalipada Ghosh Tarai Mahavidyalaya, PO: Bagdogra, Darjeeling, West Bengal 734014, India. 
properties of such chalcogenides is still unexplored till date because of their structural complexity.

The objective of the present work is to shed some light on new methodology, which may be exploited to analyze electrical measurement data. Microstructure and electrical conduction of some chalcogenide glass-nanocomposites have been explored here. Hunt's model has been used to interpret electrical measurement data, which are correlated with their microstructures.

\section{Experimental}

The conventional melt quenching method has been used to prepare the samples of chalcogenide glassy alloys of composition, $\mathrm{xAg}_{2} \mathrm{~S}-(1-\mathrm{x})(0.5 \mathrm{~S}-0.5 \mathrm{Te})$, with $\mathrm{x}=0.35$ and 0.45 , from reagent grade chemicals $\mathrm{Ag}_{2} \mathrm{~S}$, $\mathrm{S}$ and Te of high purity (Adrich 99.9\%). The chemicals in the appropriate proportions were mixed using a mortar and sealed in quartz ampoules under a vacuum of $10^{-3}$ Torr. The mixture of chemicals in the sealed ampoules was then heated at $200^{\circ} \mathrm{C}$ for one hour in a furnace. Though the melting temperature of $\mathrm{Ag}$ and $\mathrm{Te}$ is high, the melting temperature $\left(200^{\circ} \mathrm{C}\right)$ of the mixture becomes much less because of heat of mixture, developed in the resultant compositions. To obtain glassy samples, the melt was quickly quenched in ice. The as-prepared samples were then ground into fine powder in a mortar. The powder form of glassy samples is kept in pelletizer for $1 \mathrm{~h} 30 \mathrm{~min}$ under a pressure of $80 \mathrm{~kg} /$ $\mathrm{cm}^{2}$ to form pellets. They are not pure glass. Different nanophases are dispersed in the amorphous glassy matrices, which are confirmed from TEM studies. The amorphous and partially crystalline natures of the as-prepared samples are confirmed by X-ray diffraction study. The present as-prepared samples may be termed as chalcogenide glass-nanocomposites. To carry out dielectric relaxation and electrical conductivity of them, electrical measurements have been carried out using Hioki (3532-50) high precision LCR meter in the frequency range $42 \mathrm{~Hz}$ to $5 \mathrm{MHz}$ at various temperatures (433-523 K).

\section{Results and discussion}

The XRD patterns of current samples are shown in Fig. 1a, $b$ for $x=0.35$ and 0.45 respectively. It is obvious from Fig. 1 that the all the as-prepared samples are of polycrystalline nature. The presence of sharp peaks in Fig. 1 is the manifestation of long-range order or crystalline nature [20]. Different observed peaks are (110), (11-2), (021), (21-1), (111), (12-1), (022), (013), (112), (031), (30-4) and (311), which are developedfor the formation of $\mathrm{Ag}_{2} \mathrm{~S}_{2} \mathrm{Ag}_{2} \mathrm{Te}$ and $\mathrm{AgTe}_{3}$ nanocrystallites [21-24] respectively. Figure 1 also exhibits that the polycrystalline nature of the as-prepared samples increases as we move from $x=0.35$ to $x=0.45$. The crystallite size has been estimated from the full width at half maxima (FWHM) of the single diffraction peak using the Debye-Scherer relation [25]. The distribution of nanocrystallites is presented in Fig. 1c, which indicates that the size of nanocrystallite decreases as increase from 0.35 to 0.45 . It is also mentioned that the nature of distribution of dispersed nanocrystallies is homogeneous and Gaussian in nature as shown in Fig. 1c. This result may be correlated with their structures. Formation of crystallographic irregularity or a defect inside the present system is expected to be helpful for electrical conduction. Here, the defects are supposed to be localised states, which may be favourable for polaron conduction as the polarons may hop between localised states.

Figure 2 represents complex impedance plots [20] at a fixed temperature $483 \mathrm{~K}$. The semicircular portion contributes to the resistivity of the samples under consideration. In this high temperature domain, polarization effects are no longer observed [20]. The temperature dependent dc electrical conductivity of present system is shown in the inset if Fig. 2, which indicates non-linear decrement of dc conductivity with $\mathrm{Ag}_{2} \mathrm{~S}$ content. It can be anticipated fro this result that higher conduction process of sample with higher $\mathrm{Ag}_{2} \mathrm{~S}$ may be taking place via other processes such as tunnelling [20]. It can also be predicted from the nature of thermally activated dc conductivity that the present system is an amorphous semiconductor, where the conduction mechanism is controlled by polarons or variable range hopping of carriers involving several comparable activation energies [26].

To interpret dc conductivity data of as-prepared samples at low temperature, Mott's variable range hopping model [26-28] can be used as: $\sigma=A \exp \left[-\left(T_{0} / T\right)^{0.25}\right.$, where $A$ and $T_{0}$ are constants and $T_{0}$ is given by: $T_{0}=16 \mathrm{a}^{3}$ / $k N\left(E_{F}\right)$, where $N\left(E_{F}\right)$ is the density of states at the Fermi level and $a^{-1}$ is the localization length. At a temperature below Debye temperature, using the value of $a^{-1}=10 \AA$ for localized states [26-28], the values of $N\left(E_{F}\right)$ have been estimated and presented in Table 1. It is noted from Table 1 that the value of $\mathrm{N}\left(\mathrm{E}_{\mathrm{F}}\right)$ decreases with $\mathrm{Ag}_{2} \mathrm{~S}$ content $(x)$. This result directly indicates that tunnelling of polaron conduction or other processes must be responsible at higher $\mathrm{Ag}_{2} \mathrm{~S}$ doped samples with less contribution of polaron-hopping conduction in electrical conductivity, which can be validated from Fig. 2.

Here, the charge carriers are electrons, but their mobility is of the same order of magnitude as the mobility of ions in highly conducting solid electrolytes. Therefore, a description of the electronic properties of present system is not possible in terms of standard band theory $[26,27]$. The experimental findings can, however, be explained by 


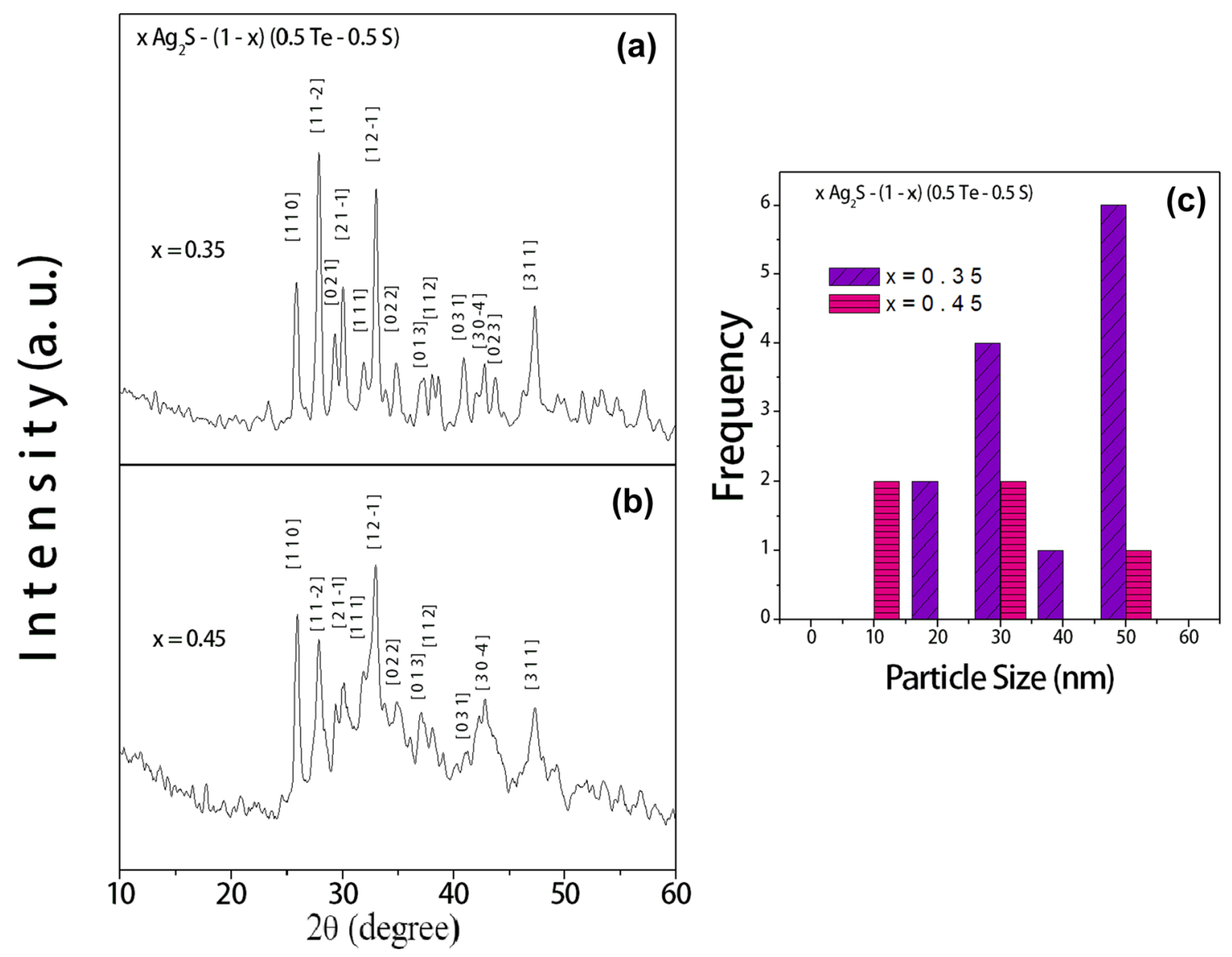

Fig. 1 XRD for $\mathbf{a} \mathrm{x}=0.35$ and $\mathbf{b} \mathrm{x}=0.45$; $\mathbf{c}$ distribution of nanocrytllites, dispersed in the as-prepared samples

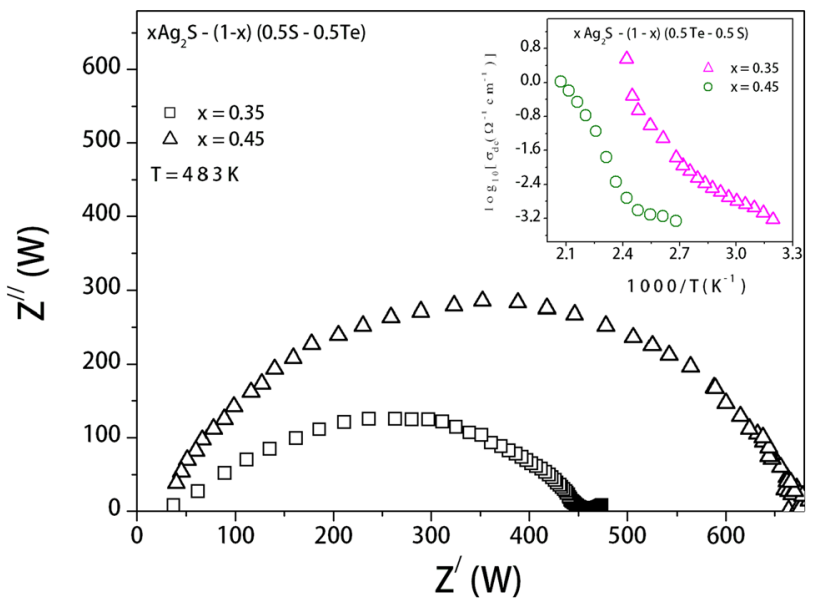

Fig. 2 Complex impedance plots of as-prepared samples. Thermally activated dc conductivity is depicted in the inset introducing the concept of polarons [26, 27]. Polarons are charge carriers trapped by self-induced lattice distortions which extend over their nearest surroundings $[26,27]$. The transport of these quasi-particles consists of phonon assisted hopping processes $[26,27]$. Extensive studies have been carried out on these some semiconducting glassy system owing to interests in their conduction mechanism and glass structure [28].

The morphological insight of the as-prepared samples for $x=0.35$ and 0.45 has been established by transmission electron micrographs (TEM) as presented in Fig. 3a, $\mathrm{d}$ respectively. High resolution TEM and selected area diffraction (SAED) patters for sample $\mathrm{x}=0.35$ and 0.45 are presented in Fig. 1b, c and Fig. 1e, f respectively. Analysis of Fig. 3a-f along with their interplanner spacing (d values) revealed that $\mathrm{Ag}_{2} \mathrm{~S}, \mathrm{Ag}_{2} \mathrm{Te}$ and $\mathrm{AgTe}_{3}$ nanocrystallites [21-24] have been developed. It is also noted from Fig. $3 a$ that $36 \mathrm{~nm}, 51 \mathrm{~nm}$ and $52 \mathrm{~nm}$ sized crystallites have been formed for $\mathrm{Ag}_{2} \mathrm{~S}, \mathrm{Ag}_{2} \mathrm{Te}$ and $\mathrm{AgTe}_{3}$ nanophases respectively for $x=0.35$. On the other hand, $10-20 \mathrm{~nm}$ sized nanocrystallies of similar nanophases are observed 
Table 1 Estimated values of $n, S, r, d_{f}$; activation Energy for conductivity relaxation, glass transition temperature, decoupling index and density of states at Fermi level

\begin{tabular}{lllllllll}
\hline $\mathrm{x}$ & $\mathrm{n}( \pm 0.05)$ & $\mathrm{S}( \pm 0.005)$ & $\begin{array}{l}\mathrm{r}=\mathrm{n}+1-\mathrm{d}_{\mathrm{f}} \\
( \pm 0.05)\end{array}$ & $\mathrm{d}_{\mathrm{f}}( \pm 0.05)$ & $\begin{array}{l}\text { Activation energy } \\
\left(\mathrm{E}_{\mathrm{m}}\right)(\mathrm{eV})( \pm 0.05)\end{array}$ & $\mathrm{T}_{\mathrm{g}}\left({ }^{\circ} \mathrm{C}\right)( \pm 1)$ & $\begin{array}{l}\log _{10}\left[\mathrm{R}_{\mathrm{\tau}}\right. \\
\left.\left(\mathrm{T}_{\mathrm{g}}\right)\right]( \pm 0.05)\end{array}$ & $\mathrm{N}\left(\mathrm{E}_{\mathrm{F}}\right)\left(\mathrm{eV} \mathrm{V}^{-1} \mathrm{~cm}^{-3}\right)( \pm 0.01)$ \\
\hline 0.35 & 1.06 & 0.45 & 0.14 & 1.92 & 0.43 & 180 & 13 & $6.93726 \times 10^{34}$ \\
0.45 & 1.32 & 1.03 & 0.09 & 2.23 & 0.61 & 190 & 12.7 & $2.98063 \times 10^{35}$ \\
\hline
\end{tabular}

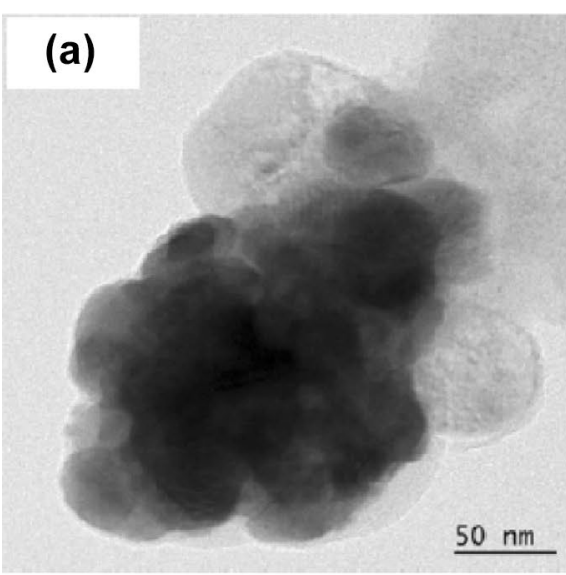

(d)

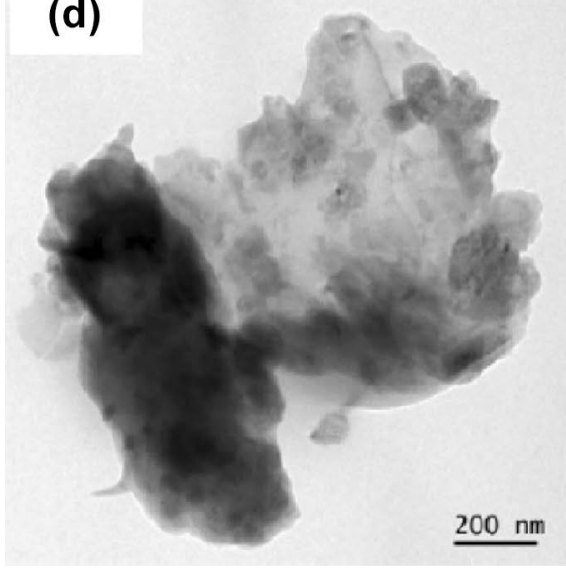

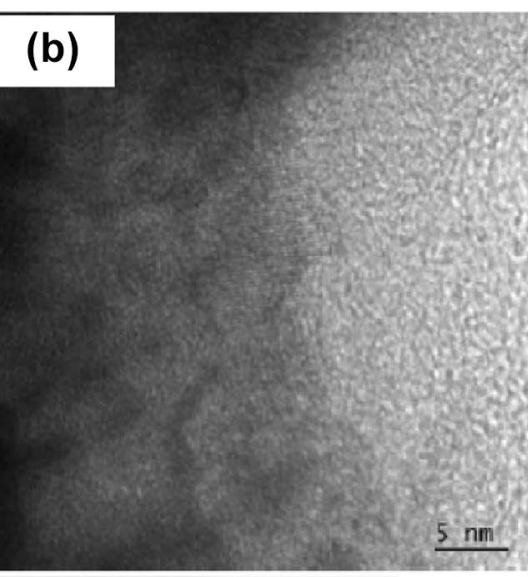

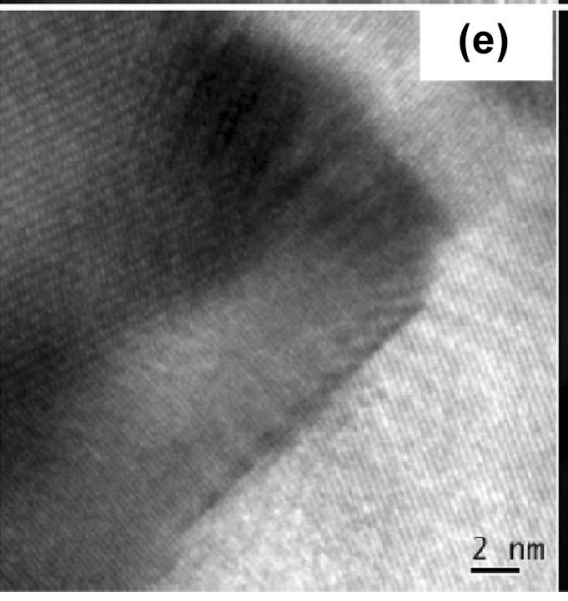

\section{(c)}
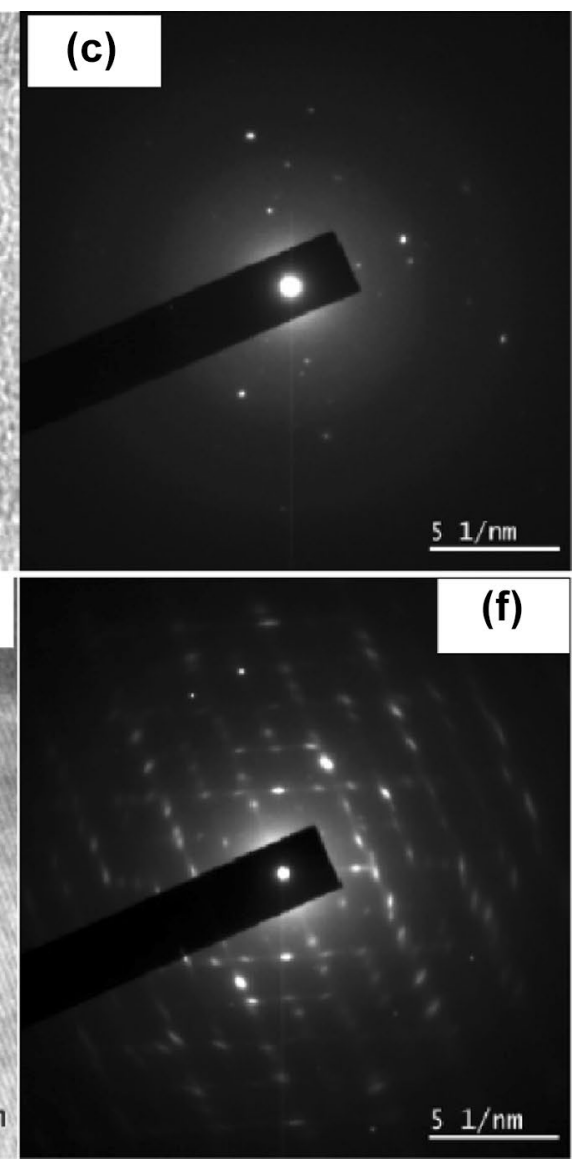

Fig. 3 a-c Particle distribution, high resolution TEM and selected area diffraction (SAED) patters respectively for sample $\mathrm{x}=0.35$; $\mathbf{d}-\mathbf{f}$ Particle distribution, high resolution TEM and selected area diffraction (SAED) patters respectively for sample $\mathrm{x}=0.45$

in the sample, $x=0.45$ as shown in Fig. $3 d$. More prominent crystalline planes are observed as we move from Fig. 3b-e. It is also clear from Fig. 3c, f (SAED) that polycrystalline nature of the as-prepared samples increases as we move from $x=0.35$ to $x=0.45$. XRD results can be employed to explore more insight of the as-prepared samples. For this purpose, the dislocation density (length of dislocation lines per unit volume of the partially crystalline materials) [29-32] has been estimated, since it is related to the formation of crystallographic irregularity or a defect inside the materials [33]. The dislocation density $(\delta)$ can be presented as [33]: $\delta=\frac{1}{d_{c}^{2}}$

where, $d_{c}$ is the average size of the crystallite in $n m$. The values of dislocation density $(\delta)$ are estimated to be $15 \times 10^{-4} \mathrm{~cm}^{-2}$ and $83 \times 10^{-4} \mathrm{~cm}^{-2}$ for $\mathrm{x}=0.35$ and 0.45 respectively. It is observed from the estimated data that as the average size of nanocrystallites decreases, dislocation density increases. Higher value of dislocation density may indicate higher order of structural defects, which may produce higher degree of structural alterations. So, large number of defects for $\mathrm{x}=0.45$ is expected to resist 
its electrical conduction via hopping of polarons due to large number of defects.

The complex electric modulus spectrum $[16,34]$ should explore the electrical relaxation and microscopic information of such glassy systems, which may directly reveal dynamic properties of the present samples alone by suppressing the polarization effects at electrode-electrolyte interface. The complex electric modulus is defined as the reciprocal of the complex permittivity $[16,34]$ and is represented as:

$M^{*}=\left(\varepsilon^{*}\right)^{-1}$

$M^{*}=M^{\prime}+i M^{\prime \prime}$

$M^{*}=\varepsilon^{\prime} /\left[\left(\varepsilon^{\prime}\right)^{2}+\left(\varepsilon^{\prime \prime}\right)^{2}\right]+i \cdot \varepsilon^{\prime \prime} /\left[\left(\varepsilon^{\prime}\right)^{2}+\left(\varepsilon^{\prime \prime}\right)^{2}\right]$

where $M^{*}$ is the complex modulus, $\varepsilon^{*}$ is the dielectric permittivity, $\mathrm{M}^{\prime}$ is the real and $\mathrm{M}^{\prime \prime}$ is the imaginary parts of the electric modulus. Figure 4a shows the frequency dependence of imaginary parts of the electric modulus for $\mathrm{x}=0.35$. Similar nature for $\mathrm{M}^{\prime \prime}$ plots have been obtained for the system, $x=0.45$. It can be observed from Fig. $4 a$ that with the increase of temperature the $\mathrm{M}^{\prime \prime}$ peak has been shifted to higher frequencies, which indicates thermally activated nature. The shifting of $\mathrm{M}^{\prime \prime}$ peak is an indication of the system stabilization in a short time for an external force at elevated temperature $[16,34]$.

The AC conductivity spectra for a particular composition $x=0.35$ have been presented in Fig. 4b. It is observed in Fig. $4 \mathrm{~b}$ that conductivity spectra do not change in the low frequency region, which may correspond to the DC conductivity [27, 35]. Hopping of polaron [27] may contribute to the drift, which is the possible reason for this frequency independent conductivity in the low frequency regime. It is also observed from Fig. $4 \mathrm{~b}$ that dispersion starts from crossover or hopping frequency in between flat DC conductivity and AC conductivity. Dispersion in the higher frequencies is expected to happen due to both hopping as well as diffusion of polarons [27]. Similar nature of conductivity spectra is achieved for $x=0.45$. Almond-West Formalism (power law model) [36-38] can be used to analyze the conductivity spectra at various temperatures as

$\sigma(\omega)=\sigma_{\mathrm{dc}}\left[1+\left(\omega / \omega_{\mathrm{H}}\right)^{\mathrm{n}}\right]$

which is the combination of the DC conductivity $\left(\sigma_{\mathrm{dc}}\right)$, hopping frequency $\left(\omega_{H}\right)$ and a fractional power law exponent (n). To get sufficient information of conducting system [36-38], this model has been used to fit the experimental conductivity data in Fig. 4b. The average values of power law exponents $(\mathrm{n})$ are presented in Table 1. The average
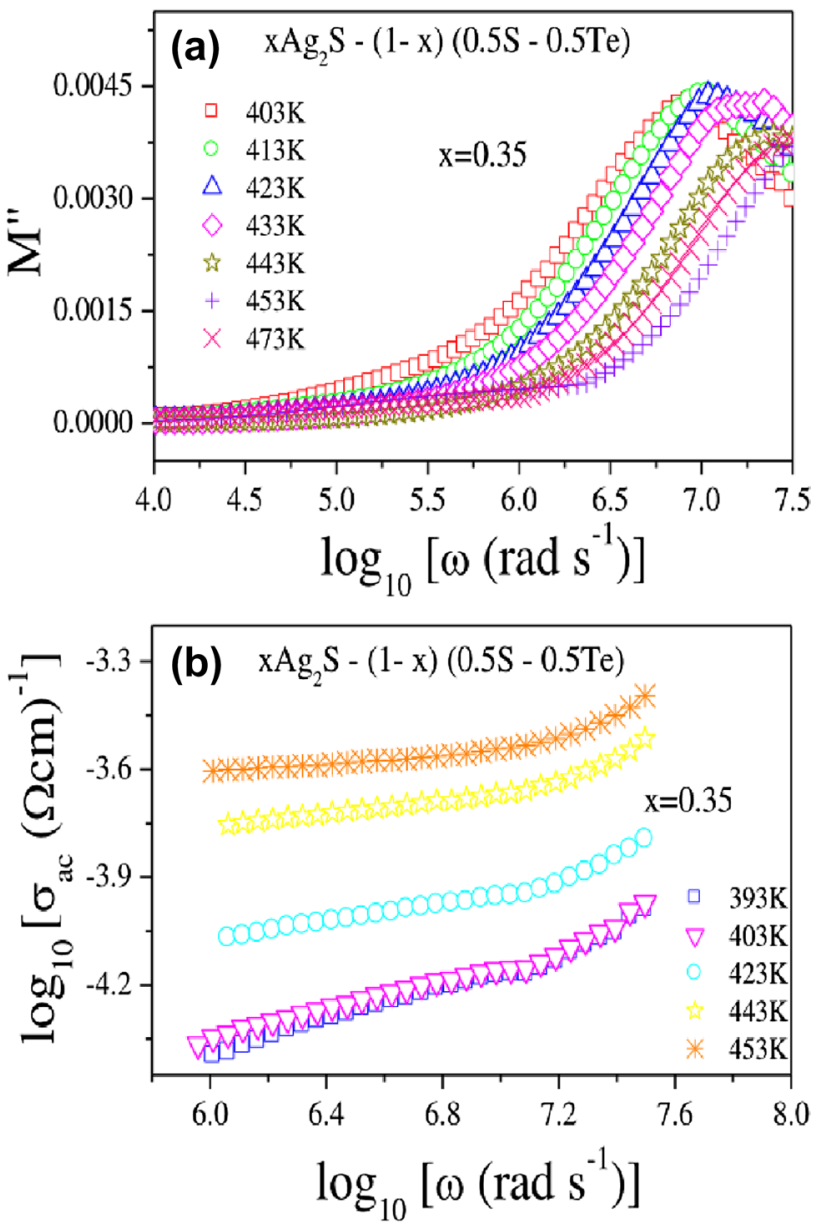

Fig. 4 a Imaginary modulus spectra for $x=0.35$ and $\mathbf{b}$ AC conductivity spectra for $x=0.35$ at various temperatures

value of power law exponent ( $\mathrm{n}$ ) is found to increase with $\mathrm{Ag}_{2} \mathrm{~S}$ doping in the present system. As the value of $\mathrm{n}$ exceeds unity for $\mathrm{x}=0.35$ and higher for $\mathrm{x}=0.45$, it can be predicted from the values of " $n$ " that polaron conduction may correspond to the percolation motion [20,39]. This percolation is expected to make collision, which may lose energy of the present system as well as conductivity.

To analysis the dielectric relaxation processes in the present glassy system, Hunt's model $[33,34]$ has been considered to analyse electrical measurement data. According to Hunt's model $[40,41]$ the total conductivity can be expressed in two different frequency domains, $\omega<\omega_{m}$ and $\omega>\omega_{m}$ where $\omega_{m}$ represents the peak frequency in dielectric loss plots (Fig. 4a). In the high frequency region $\left(\omega>\omega_{m}\right)$, the hopping of carriers in pairs between charges is considered to be responsible for relaxation process, whereas in low frequency region $\left(\omega<\omega_{m}\right)$ the relaxation process can be described as the transportation of individual particles over macroscopic distance in clusters [42]. The conductivity in these two regions can be expressed as 
$\sigma_{t}(\omega)=\sigma_{\mathrm{dc}}\left(1+A\left(\omega / \omega_{\mathrm{m}}\right)^{\mathrm{s}}\right)$ for $\omega>\omega_{\mathrm{m}}$

$\sigma_{t}(\omega)=\sigma_{\mathrm{dc}}\left(1+\mathrm{K}(\mathrm{d})\left(\omega / \omega_{\mathrm{m}}\right)^{\mathrm{r}}\right)$ for $\omega<\omega_{\mathrm{m}}$

where, $r=1+d-d_{f}, d$ is the dimensionality of space containing pertinent clusters, $d_{f}$ is the functional dimensionality of clusters, $A$ and $K(d)$ are constants. Here, $d$ may be considered to be " $n$ ". The basis of this approximation is that the percolation must involve polaron conduction through clusters via hopping and diffusion. Estimated characteristic frequency $\left(\omega_{m}\right)$ of the dielectric loss for the present glassy system is mentioned in Fig. 4b. The experimental data in Fig. 4b have been fitted well using Eqs. (6) and (7) in two frequency domains respectively. This fitting provides the values of "s" and " $r$ ", which are presented in Table 1. The estimated values of " $d_{f}$ " are also included in Table 1. It is clear from Table 1 that $d_{f}$ is found to increase with $x$. Higher $d_{f}$ values indicate higher dimensionality of clusters. It is clear from TEM micrographs in Fig. 3b, e that more dispersed nanocrystallites are appeared in the sample, $x=0.45$. This experimental evidence directly validates the results, obtained from Hunt's model $[40,41]$.

To get more microscopic information, we consider peak frequency $\left(\omega_{\mathrm{m}}\right)$, which can be presented using Arrhenius temperature dependence relation $[34,41,42]$ as:

$\omega_{m}=\omega_{0} \exp \left[-\left(W_{f} / K_{B} T\right)\right]$

where, $\omega_{m}$ is the peak frequency of the dielectric loss, $W_{f}$ is the activation energy related with dielectric loss process, $\mathrm{K}_{\mathrm{B}}$ is the Boltzmann constant and $\mathrm{T}$ is the absolute temperature. In Fig. 5, thermally activated nature of peak frequency $\left(\omega_{\mathrm{m}}\right)$ has been presented. The best linearly fitted data evolves the corresponding activation energy related to the dielectric loss process, which are included in Table 1. It can be observed from the Table 1 that the activation energy related to the dielectric loss increases with the increase of $\mathrm{Ag}_{2} \mathrm{~S}$ content in the system. This higher activation energy may indicate higher relaxation time for $x=0.45$.

The conductivity relaxation frequency $\left(\omega_{\mathrm{m}}\right)$, corresponding to $M_{\text {max }}^{\prime \prime}$ provides the most probable conductivity relaxation time $\tau_{m}$ by the condition $\omega_{m} \tau_{m}=1$ [43]. To shed some light on the electrical relaxation process, decoupling index, $R_{\tau}\left(T_{g}\right)$ [43] has been estimated as the ratio of the average structural relaxation time, $\tau_{s}\left(T_{g}\right)$, to the average conductivity relaxation time $\tau_{m}\left(T_{g}\right)$ at the glass transition temperature $T_{g}$. This quantity $R_{\tau}\left(T_{g}\right)$ exhibits the extent to which the motion of the polarons is decoupled from the viscous motion of the glassy network. The estimated values of $T_{g}$ and $R_{\tau}\left(T_{g}\right)$ are presented in Table 1. The structural relaxation time is assumed to be $\tau_{s}\left(T_{g}\right)=200 \mathrm{~s}$

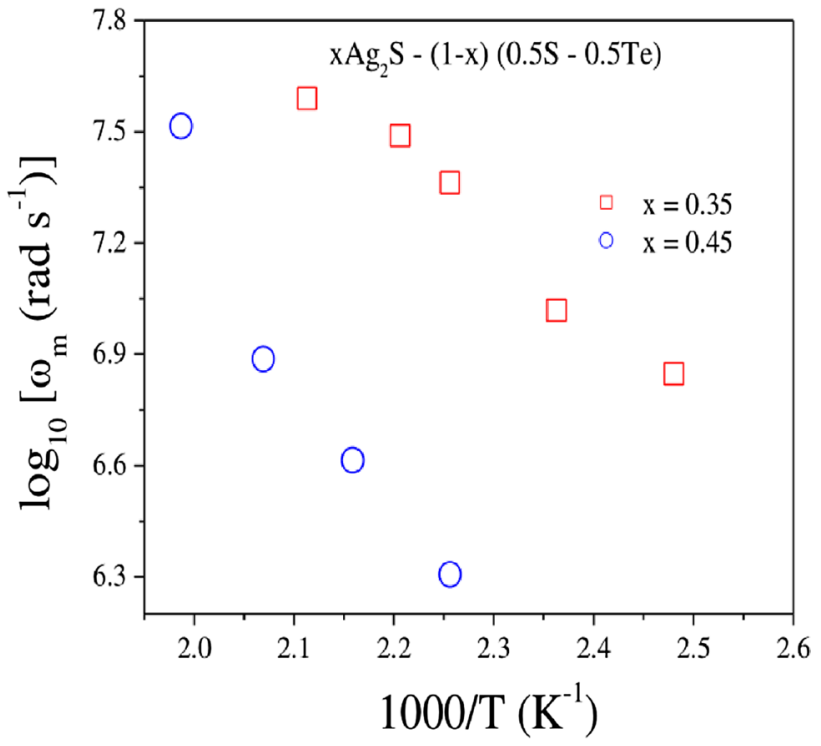

Fig. 5 Variation of peak frequency with reciprocal temperature for $\mathrm{x}=0.35$ and 0.45

[43]. It is noteworthy from Table 1 that the decoupling index decreases with $\mathrm{Ag}_{2} \mathrm{~S}$ content. This result suggests that the polaron motion is decoupled more and more from the viscous motion of the glassy matrix as the content of $\mathrm{Ag}_{2} \mathrm{~S}$ is decreased in the composition, suggesting the decrease of the dc conductivity with the increase of the $\mathrm{Ag}_{2} \mathrm{~S}$ content.

\section{Conclusion}

Dielectric properties and electrical conductivity of $\mathrm{Ag}_{2} \mathrm{~S}$ doped Sulphur-Tellurium Chalcogenide glassy system has been studied. Hunt's model is successfully applied to explain dielectric relaxation data, which is also validated using TEM micrographs and their microstructures. Activation energies corresponding to peak frequency $\left(\omega_{m}\right)$ have been calculated from dielectric loss and complex modulus measurements. Observations show the enhancement of activation energies and hence the decrease of conductivity with the increase of $\mathrm{Ag}_{2} \mathrm{~S}$ in the Silver Sulphide doped Sulphur-Tellurium chalcogenide glassy system.

Acknowledgements The financial assistance for the work by the DSTCRG (Department of Science \& Technology, Govt. of India) via Sanction No. CRG/2018/000464 is thankfully acknowledged.

\section{Compliance with ethical standards}

Conflict of interest There is no conflict of interest of the present work. 


\section{References}

1. Cha D, Kim H-J, Hwang Y, Jeong JC, Kim J-H (2012) Fabrication of molded chalcogenide-glass lens for thermal imaging applications. Appl Opt 51:5649

2. Petersen C, Møller U, Kubat I, Zhou B, Dupont S, Ramsay J, Benson T, Sujecki S, Abdel-Moneim N, Tang Z, Furniss D, Seddon A, Bang $O$ (2014) Mid-infrared supercontinuum covering the 1.4-13.3 um molecular fingrprint region using ultra-high NA chalcogenide step-index fibre. Nat Photonics 8:830-834

3. Heo J, Chung WJ (2014) Rare-earth-doped chalcogenide glass for lasers and amplifiers Chalcogenide Glasses. Woodhead Publishing, Sawston, pp 347-380

4. Fan B, Xue B, Luo Z, Zhang X-H, Ma H, Calvez L (2019) Pressure dependence of interfacial resistance in pellets made from $\mathrm{GeS}_{2}-\mathrm{Ga}_{2} \mathrm{~S}_{3}-\mathrm{Li}_{2} \mathrm{~S}$-Lil glass powder. J Am Ceram Soc 102:1122

5. Halyan V, Kevshync AH, Ivashchenkod IA, Lakshminarayanae G, Shevchukf MV, Fedorchuk A, Piasecki M, Kityk I (2016) Effect of temperature on the structure and luminescence properties of $\mathrm{Ag}_{0.05} \mathrm{Ga}_{0.05} \mathrm{Ge}_{0.95} \mathrm{~S}_{2}-\mathrm{Er}_{2} \mathrm{~S}_{3}$ glasses. J Lumin 181:315

6. El-Naggar AM, Albassam AA, Myronchuk GL, Zamuruyeva OV, Kityk IV, Rakus P, Parasyuk OV, Jędryka J, Pavlyuk V, Piasecki M (2018) Photoconductivity and laser operated piezoelectricity the Ag-Ga-Ge-(S, Se) crystals and solid solutions. Mater Sci Semicond Process 86:101

7. Sujatha B, Reddy N, Chakradhar R (2010) Dielectric relaxation and ion transport in silver-boro-tellurite glasses. Philos Mag 90:2635

8. Wang RY, Tangirala R, Raoux S, Jordan-Sweet J, Milliron DJ (2012) Ionic and electronic transport in $\mathrm{Ag}_{2} \mathrm{~S}$ nanocrystal- $\mathrm{GeS}_{2}$ matrix composites with size-controlled $\mathrm{Ag}_{2} \mathrm{~S}$ nanocrystals. Adv Mater 24:99

9. Muthusamy T, Bhattacharyya AJ (2016) Antimony sulphoiodide (SbSI), a narrow band-gap non-oxide ternary semiconductor with efficient photocatalytic activity. RSC Adv 6:105980

10. Kassem M, Le Coq D, Bokova M, Bychkov E (2010) Chemical and structural origin of conductivity changes in CdSe-Agl- $-\mathrm{As}_{2} \mathrm{Se}_{3}$ glasses. Solid State lonics 181:466

11. Hassanien AS, Akl A (2016) Electrical transport properties and Mott's parameters of chalcogenide cadmium sulphoselenide bulk glasses. J Non Cryst Solids 432:471

12. Belin R, Taillades G, Pradel A, Ribes M (2000) lon dynamics in superionic chalcogenide glasses: Complete conductivity spectra. Solid State lonics 136:1025

13. Studenyak I, Yuriy N, Kranjcec M, Solomon AM, Orliukas A, Kežionis A, Kazakevicius E, Salkus T (2014) Electrical conductivity studies in $\left(\mathrm{Ag}_{3} \mathrm{AsS}_{3}\right)_{x}\left(\mathrm{As}_{2} \mathrm{~S}_{3}\right)_{1-\mathrm{x}}$ superionic glasses and composites. J Appl Phys 115:33702

14. Suresh S (2014) Investigations on electrical properties of cadmium telluride thin films by chemical bath deposition technique. J Non Cryst Solids 6:47

15. Y. Zhang, Q. Jiao, B. Ma, Z. Xianghua, X. Liu, S. Dai, J. Am. Ceram. Soc. (in press)

16. Long AR (1982) Frequency-dependent loss in amorphous semiconductors. Adv Phys Adv Phys 31:553

17. Ahmad-Bitar R, Arafah D-E (1998) Processing effects on the structure of $\mathrm{CdTe}, \mathrm{CdS}$ and $\mathrm{SnO}_{2}$ thin films. Sol Energy Mater Sol Cells 51:83

18. Sen Ram I, Singh DR, Singh P, Singh K (2013) Effect of Pb addition on dielectric relaxation in $\mathrm{Se}_{80} \mathrm{In}_{20}$ glassy system. J Alloys Compd $552: 480$

19. Atyia $\mathrm{H}$ (2014) Electrical conductivity and dielectric relaxation of bulk $\mathrm{Se}_{70} \mathrm{Bi}_{(30-x)} \mathrm{Te}_{\mathrm{x}}, \mathrm{x}=(0,15)$ chalogenide glasses. J Non Cryst Solids 391:83
20. Elliott SR (1986) Physics of amorphous materials. Wiley, Incorporated, New York

21. Shafizade RB, Aliev FI, Ivanova IV, Kazinets MM, Nuriev IR, Sultanov RM (1973) Chemlnform Abstract: electronographic examination of phase formation in system Ag-S. Inorg Mater 9:975

22. Frueh AJJ (1961) The use of zone theory in problems of sulfide mineralogy, Part III; Polymorphism of $\mathrm{Ag}_{2} \mathrm{Te}$ and $\mathrm{Ag}_{2} \mathrm{~S}$. Am Mineral 46:654

23. Van Der Lee A, De Boer JL (1993) Redetermination of the structure of hessite, $\mathrm{Ag}_{2} \mathrm{Te}-$ III. Acta Crystallogr C 49:1444

24. Zabel M, Rau F, Von Krziwanek F, Panzer B, Range KJ (1982) A novel three-dimensional tellurium array: high-pressure synthesis and crystal structure of $\mathrm{AgTe}_{3}$. Angew Chem Inr Ed Engl 21(9):706-707

25. Singhal S, Kaur J, Namgyal T, Sharma R (2012) Cu-Doped ZnO nanoparticles: synthesis, structural and electrical properties. Phys B 407:1223

26. Ghosh A (1990) Electrical transport properties of molybdenum tellurite glassy semiconductors. Philos Mag 61:87

27. Mott NF, Davis EA (2012) Electronic processes in non-crystalline materials, 2nd edn. Clarendon Press, Oxford

28. S. Bhattacharya, Phys. Lett $A$ (in Press)

29. Acharya A, Bhattacharya K, Ghosh CK, Bhattacharya S (2020) Microstructures and charge carrier transport of some $\mathrm{Li}_{2} \mathrm{O}$ doped glassy ceramics. Mater Lett 265:127438

30. Bhattacharya S (2019) Metal oxide glass nanocomposites. Elsevier Publications, New York

31. Ojha S, Roy M, Chamuah A, Bhattacharya K, Bhattacharya S (2020) AC conductivity and dielectric behavior of Cu-S-Te chalcogenide glassy system. Mater Lett 258:126792

32. Venkateswarlu D, Thangavelu SMA, Rameshbabu N (2014) Estimation of crystallite size, lattice strain and dislocation density of nanocrystalline carbonate substituted hydroxyapatite by $\mathrm{x}$-ray peak variance analysis. Proc Mater Sci 5:212

33. Frederick Harrington G, Cavallaro A, McComb DW, Skinner S, Kilner JA (2017) The effects of lattice strain, dislocations, and microstructure on the transport properties of YSZ films. Phys Chem Chem Phys 19:14319

34. Macdonald JR, Kenan WR (1987) Impedance spectroscopy: emphasizing solid materials and systems. Wiley, New York

35. Ghosh S, Ghosh A (2007) Electrical conductivity and relaxation in mixed alkali tellurite glasses. J Chem Phys 126:184509

36. Almond DP, Duncan GK, West AR (1983) The determination of hopping rates and carrier concentrations in ionic conductors by a new analysis of ac conductivity. Solid State lonics 8:159

37. Ghosh A, Pan A (2000) Scaling of the conductivity spectra in ionic glasses: dependence on the structure. Phys Rev Lett $84: 2188$

38. Abdelghany AM, El-Damrawi G, Oraby AH, Madshal MA (2019) $\mathrm{AC}$ conductivity and dielectric properties of $\mathrm{CoO}$ doped SrO$\mathrm{P}_{2} \mathrm{O}_{5}$ glasses. Phys $\mathrm{B}$ 573:22

39. Sidebottom DL (1999) Dimensionality dependence of the conductivity dispersion in ionic materials. Phys Rev Lett 83:983

40. Hunt A (1992) Some universalities in the relaxation of glasses. J Non Cryst Solids 144:21

41. Hunt A (1993) Non-Debye relaxation and the glass transition. J Non Cryst Solids 160:183

42. Murawski L, Barczyński R (1996) Dielectric relaxation in semiconducting oxide glasses. J Non-Cryst Solids 196:275

43. Bhattacharya S, Ghosh A (2005) Relaxation of silver ions in fast ion conducting molybdate glasses. Solid State Ionics 176:1243

Publisher's Note Springer Nature remains neutral with regard to jurisdictional claims in published maps and institutional affiliations. 